\title{
Peroxisome proliferator-activated receptor $\gamma$ mediates porcine placental angiogenesis through hypoxia inducible factor-, vascular endothelial growth factor- and angiopoietin-mediated signaling
}

\author{
JUZUO ZHANG, XUAN PENG, ANWEN YUAN, YANG XIE, QING YANG and LIQUN XUE \\ Department of Clinic Veterinary Medicine, College of Veterinary Medicine, \\ Hunan Agricultural University, Changsha, Hunan 410128, P.R. China
}

Received July 3, 2016; Accepted April 27, 2017

DOI: $10.3892 / \mathrm{mmr} .2017 .6903$

\begin{abstract}
Peroxisome proliferator-activated receptor (PPAR) $\gamma$ has been reported to be implicated in placentation in mice. Previous studies have demonstrated that PPAR $\gamma$ is also expressed in porcine placenta, primarily localized in vascular endothelial cells (VECs). The present study aimed to investigate the roles of PPAR $\gamma$ during porcine placental angiogenesis and examine the molecular mechanisms involved in its actions. VECs were incubated with the PPAR $\gamma$ agonist rosiglitazone and the antagonist T0070907, and their angiogenic potential was evaluated using cellular impedance, wound healing and tube formation assays. Reverse transcription-quantitative polymerase chain reaction was used to assess the mRNA expression levels of angiogenic factors, including hypoxia-inducible factors (HIFs), vascular endothelial growth factor (VEGF) isoforms, VEGF receptors (VEGFRs) and angiopoietins (Angs). The results demonstrated that the adhesive, proliferative and migratory capabilities of VECs were potentiated by rosiglitazone and suppressed by T0070907. Notably, tube formation was invariably promoted during PPAR $\gamma$ activation and blockade. The mRNA expression levels of HIF1 $\alpha$, HIF2 $\alpha$, VEGFR2, VEGF188 and Ang-1 were revealed to be
\end{abstract}

Correspondence to: Dr Liqun Xue or Dr Qing Yang, Department of Clinic Veterinary Medicine, College of Veterinary Medicine, Hunan Agricultural University, 1 Nongda Road, Changsha, Hunan 410128, P.R. China

E-mail: liqun_xue@163.com

E-mail: qingyanghn@hunau.edu.cn

Abbreviations: CD31, cluster of differentiation 31; DMSO, dimethyl sulfoxide; FCS, fetal calf serum; HIF, hypoxia-inducible factor; PIGF, placental growth factor; PPAR, peroxisome proliferator-activated receptor; sFlt1, soluble fms-like tyrosine kinase-1; T0070907, 2-chloro-5-nitro-N-4-pyridinyl-benzamide; VEC, vascular endothelial cell; VEGF, vascular endothelial growth factor; VEGFR, VEGF receptor; vWF, von Willebrand factor

Key words: vascular endothelial cells, angiogenesis, peroxisome proliferator-activated receptor $\gamma$, angiogenic factors upregulated following treatment of VECs with rosiglitazone, whereas they were downregulated following treatment with T0070907. However, the mRNA expression levels of placental growth factor and VEGF120 were consistently downregulated following PPAR $\gamma$ activation and blockade, whereas VEGF164 mRNA levels remained unaltered. The results of the present study suggested that PPAR $\gamma$ may mediate porcine placental angiogenesis, by interfering with HIF-, VEGF- and angiopoietin-mediated signaling pathways.

\section{Introduction}

Vascular development is guided by two distinct mechanisms: Vasculogenesis, during which a primary vascular plexus is formed by angioblasts and hemopoietic cells, and angiogenesis, during which new capillaries are generated from existing blood vessels. Angiogenesis is tightly regulated by pro- and antiangiogenic molecules $(1,2)$ and can be divided into the following steps: Endothelial cell proliferation and migration, tube formation, vessel elongation and maturation (3). Numerous factors are involved in the regulation of angiogenic processes, including the various vascular endothelial growth factor (VEGF) isoforms and their receptors (VEGFRs) (4,5), angiopoietins (Ang1 and Ang2) and their receptors (6,7), fibroblast growth factors (8) and hypoxia-inducible factors (HIFs) (9). Angiogenesis usually occurs under low $\mathrm{O}_{2}$ conditions; in the human placenta, angiogenesis progresses in a $\sim 1.5-8 \% \mathrm{O}_{2}$ environment (10). HIFs are hypoxia-responsive transcription factors that act as $\mathrm{O}_{2}$ sensors in mammalian cells; within the HIF family, HIF1 $\alpha$ and HIF $2 \alpha$ have been implicated in early placental angiogenesis $(11,12)$.

VEGFA and placental growth factor (PlGF) are members of the VEGF family, and are critical for the regulation of angiogenesis (13). The VEGFA gene can undergo alternative splicing and produce several splice variants, among which VEGF121/VEGF120, VEGF165/VEGF164 and VEGF189/VEGF188 are the most notable and stable. The various VEGFA isoforms with distinct biochemical properties may serve distinct roles during the various stages of angiogenesis (14-16). VEGFRs belong to the receptor tyrosine kinase family, and include VEGFR1, encoded by the FLT1 gene, VEGFR2, encoded by the KDR gene, and soluble fms-like 
tyrosine kinase-1 (sFlt1), an alternatively spliced form of VEGFR1, all of which have been implicated in angiogenesis (17).

Peroxisome proliferator-activated receptor (PPAR)- $\gamma$ belongs to the superfamily of nuclear receptors, and is a ligand-activated transcription factor predominantly expressed in adipose tissue and endothelial cells $(18,19)$. PPAR $\gamma$ has been implicated in placentation in mice, as PPAR $\gamma^{-/-}$embryos exhibit severe impairments in placental vascularization, leading to increased mortality $(20,21)$. In addition, a role for PPAR $\gamma$ has been suggested during the differentiation of human labyrinthine trophoblasts, which may be associated with HIF signaling (22). Furthermore, the synchronized activation of G-protein coupled receptor 120 and PPAR $\gamma$ has been demonstrated to enhance VEGF production in adipocytes (23). Therefore, it may be hypothesized that PPAR $\gamma$ is implicated in porcine placental angiogenesis, and the molecular mechanisms underlying its actions involve HIF-, VEGF- and angiopoietin-mediated signaling.

Vascular endothelial cells (VECs) serve key roles in numerous physiological and pathological processes, including angiogenesis, blood pressure regulation, vascular permeability, wound healing and tumor metastasis (24). PPAR $\gamma$ has previously been revealed to be expressed in porcine placenta, mainly localized in VECs, thus suggesting a role for PPAR $\gamma$ in placental vascularization (25). The present study aimed to further investigate the roles of PPAR $\gamma$ in porcine placental vascularization and explore the molecular mechanisms involved in its actions. In the present study, VECs were isolated and incubated with PPAR $\gamma$ ligands to investigate the angiogenic potential of PPAR $\gamma$ in vitro. In addition, the mRNA expression levels of components of HIF- VEGF- and angiopoietin-mediated signaling pathways were also assessed.

\section{Materials and methods}

VEC isolation and identification. All studies were approved by the Animal Care and Use Committee of Hunan Agricultural University (Hunan, China). VECs were isolated from the umbilical vein of the delivered placenta of primiparity Landrace pigs $(n=16,13$ months old) as previously described $(26,27)$, with minor modifications. Briefly, umbilical veins were collected form delivered placenta, ligated with Serrefines (Zendainc instrument, Inc., Shanghai, China) and filled with $0.1 \%$ (w/v) collagenase (Sigma-Aldrich; Merck $\mathrm{KGaA}$, Darmstadt, Germany) for digestion at $37^{\circ} \mathrm{C} 10 \mathrm{~min}$. Digested cells were collected by centrifugation at $560 \mathrm{x} \mathrm{g}$ for $5 \mathrm{~min}$ at room temperature (RT), washed with PBS, and cultured in complete medium, which contained RPMI 1640 medium (Gibco; Thermo Fisher Scientific, Inc., Waltham, MA, USA) supplemented with $10 \%$ fetal calf serum (Gibco; Thermo Fisher Scientific, Inc.) and $100 \mu \mathrm{g} / \mathrm{ml}$ penicillin/streptomycin (Gibco; Thermo Fisher Scientific, Inc.), at $37^{\circ} \mathrm{C}$ in a $5 \% \mathrm{CO}_{2}$ atmosphere. Isolated VECs were cultured for three passages before identification using immunofluorescence. Cells were fixed with 4\% paraformaldehyde (Sigma-Aldrich; Merck $\mathrm{KGaA}$ ) at RT for $30 \mathrm{~min}$, permeabilized with $0.1 \%$ Triton X-100 (Sigma-Aldrich; Merck KGaA) at RT for $10 \mathrm{~min}$, blocked using $2 \%$ bovine serum albumin (Sigma-Aldrich; Merck KgaA) at RT for $2 \mathrm{~h}$ and incubated with rabbit anti-von
Willebrand factor (vWF) (1:200; cat no. PB0273 Wuhan Boster Biological Technology, Ltd., Wuhan, China) and anti-cluster of differentiation (CD)31 (1:200; cat no. BA1346 Wuhan Boster Biological Technology, Ltd.) primary antibodies at $4^{\circ} \mathrm{C}$ overnight. Cells were then incubated with Cyanine 3-labelled Goat anti-rabbit secondary antibodies (1:100; cat no. BA1032 Wuhan Boster Biological Technology, Ltd.) at RT for $1 \mathrm{~h}$, and counterstained with $0.4 \mu \mathrm{g} / \mathrm{ml}$ DAPI (Wuhan Boster Biological Technology, Ltd.) at RT for $10 \mathrm{~min}$. Cells were incubated with rabbit immunoglobulin G (1:20; cat no. AR1010 Wuhan Boster Biological Technology, Ltd.) in place of the primary antibody to serve as the negative control. Stained cells were observed under a fluorescence microscope (Olympus Corporation, Tokyo, Japan). The positive rate of cells was determined using Image-Pro Plus software version 6.0 (Media Cybernetics, Inc., Rockville, MD, USA). Cultures between passages 3 and 6, with a positive rate of $\sim 95 \%$ were used for further experiments.

Cellular impedance assay. VEC proliferation was assessed using a cellular impedance assay. VECs were seeded into 8-well E-plates (ACEA Biosciences, Inc., San Diego, CA, USA) at a density of 7,500 cells/well and cultured overnight. Cells were cultured with complete medium, supplemented with $0.1 \%$ dimethyl sulfoxide (DMSO) (Sigma-Aldrich; Merck KGaA) as a control, the PPAR $\gamma$ agonist rosiglitazone (10 $\mu \mathrm{M}$; Sigma-Aldrich; Merck KGaA) or the PPAR $\gamma$ antagonist T0070907 (15 $\mu \mathrm{M}$; Sigma-Aldrich; Merck KGaA) respectively, as previously described $(28,29)$. Cellular proliferation was dynamically monitored using the iCELLigence ${ }^{\mathrm{TM}}$ real-time cell analysis (RTCA) system (ACEA Biosciences, Inc.) at $37^{\circ} \mathrm{C}$ in a $5 \% \mathrm{CO}_{2}$ atmosphere for $100 \mathrm{~h}$. The cell index, which reflects the adhesion, proliferation and viability of the cells through electrical impedance across interdigitated microelectrodes integrated on the bottom of the E-plates, was automatically calculated for each E-plate well using RTCA software version 1.2 (Roche Diagnostics, Basel, Switzerland) and graphs were generated in real-time using the iCELLigence $^{\text {TM }}$ system $(30,31)$. Each treatment was performed in duplicate and three independent experiments were conducted.

Scratch-wound assay. VECs were seeded into 6-well plates at a density of $2.5 \times 10^{5}$ cells/well. When the cells had reached $90 \%$ confluence, cells were washed twice with PBS and serum-starved in RPMI 1640 medium for $9 \mathrm{~h}$. The confluent cell layer was scratched with a $10 \mu \mathrm{l}$ pipette tip, detached cells were removed by washing with PBS, and cells were cultured in the presence of $10 \mu \mathrm{M}$ rosiglitazone, $15 \mu \mathrm{M}$ T0070907 or $0.1 \%$ DMSO, respectively, in RPMI 1640 medium for $24 \mathrm{~h}$. Photomicrographs of the scratch wounds were obtained using an inverted phase-contrast microscope (Olympus Corporation) equipped with a digital camera. The wound width was determined using Image-Pro Plus software version 6.0.

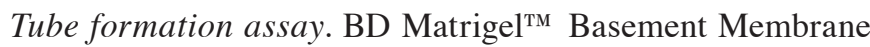
Matrix (BD Biosciences, Franklin Lakes, NJ, USA) was added into 96 -well plates (50 $\mu \mathrm{l} /$ well) and allowed to polymerize at $37^{\circ} \mathrm{C}$ for $30 \mathrm{~min}$. VECs were serum-starved overnight and seeded into 96-well plates precoated with Matrigel at a density of $2 \times 10^{4}$ cells/well, in the presence of rosiglitazone $(10 \mu \mathrm{M})$, T0070907 $(15 \mu \mathrm{M})$ or $0.1 \%$ DMSO. Tube formation images 
were captured at 6 and $10 \mathrm{~h}$ under an inverted microscope (Olympus Corporation) equipped with a digital camera, and data were analyzed using Image-Pro Plus software version 6.0. Differentiation of VECs into capillary-like tubes was assessed by two independent investigators, via counting the number of capillary branches under x100 magnification in 3 random fields/well. The tube formation index was determined via measuring the length of tubes ( $\geq 30 \mu \mathrm{m}$ ) in 3 random fields from each well.

Reverse transcription-quantitative polymerase chain reaction $(R T-q P C R)$. VECs were seeded into 6-well plates at a density of $2.5 \times 10^{5}$ cells/well and cultured in complete medium at $37^{\circ} \mathrm{C}$ in $5 \% \mathrm{CO}_{2}$ for $6 \mathrm{~h}$. Cells were then treated with serum free medium supplemented with rosiglitazone $(10 \mu \mathrm{M})$, T0070907 $(15 \mu \mathrm{M})$ or $0.1 \%$ DMSO at $37^{\circ} \mathrm{C}$ in a $5 \% \mathrm{CO}_{2}$ for $24 \mathrm{~h}$. When the cells had reached $>90 \%$ confluence, total RNA was extracted from VECs with different treatments using Takara MiniBEST Universal RNA Extraction kit (Takara Biotechnology Co., Ltd., Dalian, China), according to the manufacturer's protocol. The quantity and quality of total RNA were determined using the NanoDrop 2000 UV-Vis Spectrophotometer (Thermo Fisher Scientific, Inc., Wilmington, DE, USA). Total RNA (500 ng) was reverse transcribed into cDNA using PrimeScript ${ }^{\mathrm{TM}} 1 \mathrm{st}$ strand cDNA synthesis kit (Takara Biotechnology Co., Ltd.). qPCR results were calculated using absolute quantification with the standard curve method. Fragments of the indicated target genes (Table I) were ligated into a pMD-T18 vector (Takara Biotechnology Co., Ltd.) to create recombinant plasmids, which were amplified in E. coli JM109 cells (Takara Biotechnology Co., Ltd.). qPCR was performed using a SYBR ${ }^{\circledR}$ Premix Ex Taq ${ }^{\mathrm{TM}}$ kit (Takara Biotechnology Co., Ltd.) on a StepOne ${ }^{\mathrm{TM}}$ Real-Time PCR system (Applied Biosystems; Thermo Fisher Scientific, Inc.) under the following conditions: $95^{\circ} \mathrm{C}$ for $2 \mathrm{~min}$, followed by 40 cycles of $95^{\circ} \mathrm{C}$ for $5 \mathrm{sec}$ at $60^{\circ} \mathrm{C}$ for $30 \mathrm{sec}$, followed by melt curve analysis. The reaction volume was $20 \mu \mathrm{l}$, consisting of $10 \mu \mathrm{l}$ SYBR Premix DimerEraser, $0.4 \mu \mathrm{l}$ ROX dye, $0.2 \mu \mathrm{l}$ of each primer $(20 \mu \mathrm{M})$, $2 \mu \mathrm{l}$ cDNA templates and water up to $20 \mu \mathrm{l}$. The standard curve was obtained using 10 -fold serially diluted plasmid samples as templates, with $\mathrm{R}^{2}$ values $>0.999$. The specific primers used for PCR are presented in Table I. The data were analyzed using the comparative $\mathrm{Cq}$ method and gene expression was normalized to GAPDH (32).

Western blot analysis. VECs were seeded into 6-well plates at a density of $2.5 \times 10^{5}$ cells/well and cultured in complete medium at $37^{\circ} \mathrm{C}$ in $5 \% \mathrm{CO}_{2}$ for $6 \mathrm{~h}$. Cells were then treated with serum free medium supplemented with rosiglitazone $(10 \mu \mathrm{M})$, T0070907 $(15 \mu \mathrm{M})$ or $0.1 \%$ DMSO at $37^{\circ} \mathrm{C}$ in a $5 \%$ $\mathrm{CO}_{2}$ for $24 \mathrm{~h}$. When the cells had reached $>90 \%$ confluence, all treated cells were lysed at $4^{\circ} \mathrm{C}$ for $30 \mathrm{~min}$ in radioimmunoprecipitation assay lysis buffer (Bio-Rad Laboratories, Inc., Hercules, CA, USA) containing proteinase inhibitor cocktail (aprotinin and phenylmethanesulfonyl fluoride). Protein concentration was determined using a Bicinchoninic Acid assay with an Easy II Protein Quantitative kit (Beijing Transgen Biotech Co., Ltd., Beijing, China). Equal amounts of extracted protein samples $(30 \mu \mathrm{g})$ were separated by $10 \%$ SDS-PAGE and transferred onto nitrocellulose membranes.
The membranes were blocked with $2 \%$ bovine serum albumin at RT for $2 \mathrm{~h}$ and then incubated with an anti-PPAR $\gamma$ antibody (1:1,000) (cat no. ab19481; Abcam, Cambridge, UK) or anti-GAPDH antibody $(1: 2,000)$ (cat no. ab9484; Abcam) overnight at $4^{\circ} \mathrm{C}$. Subsequently, membranes were incubated with the HRP-conjugated Affinipure Goat Anti-Rabbit IgG (1:5,000; cat no. SA00001-2, Wuhan Sanying Biotechnology, Wuhan, China). Protein bands were visualized by enhanced chemiluminescence using SuperSignal ${ }^{\mathrm{TM}}$ West Pico Chemiluminescent Substrate (Thermo Fisher Scientific, Inc.) on a ChemiDoc ${ }^{\mathrm{TM}} \mathrm{XRS}+$ system (Bio-Rad Laboratories, Inc.). PPAR $\gamma$ blots were normalized to GAPDH and semi-quantified by densitometry using ImageJ software (v2.1.4.7; National Institutes of Health, Bethesda, MD, USA).

Statistical analysis. Data are presented as the mean \pm standard error of at least 3 independent experiments. The statistical significance of the differences between groups was assessed using one-way analysis of variance. Statistical analysis was performed using SPSS software version 19.0 (IBM Corp., Armonk, NY, USA). $\mathrm{P}<0.05$ was considered to indicate a statistically significant difference.

\section{Results}

Morphological and biochemical characteristics of VECs. As presented in Fig. 1, isolated VECs grew as confluent monolayers with typical cobblestone morphology, and had ovoid nuclei with 1 or 2 nucleoli. The VEC markers VWF- and CD31 were positively stained in the nuclei (Fig. 1). No specific staining was detected in negative control cells.

Roles of PPAR $\gamma$ in VEC adhesion and proliferation. In the present study, the mRNA and protein expression levels of $\operatorname{PPAR} \gamma$ were revealed to be upregulated in VECs following treatment with the PPAR $\gamma$ agonist rosiglitazone, whereas they were downregulated following treatment with the antagonist T007097 (Fig. 2). A cellular impedance assay demonstrated that following treatment with rosiglitazone, the adhesive and proliferative capabilities of VECs were enhanced, whereas treatment with T0070907 suppressed VEC adhesion and proliferation (Fig. 3).

Roles of PPAR $\gamma$ in VEC migration. The migratory capabilities of VECs were investigated using a wound healing assay, as previously described (33). As presented in Fig. 4, VEC migration was significantly enhanced following treatment with rosiglitazone for $24 \mathrm{~h}$ compared with control cells $(\mathrm{P}<0.05)$. Inhibition of PPAR $\gamma$ with T0070907 was revealed to decrease the migratory activity of VECs $(\mathrm{P}<0.01)$.

Roles of PPAR in VEC capillary-like tube formation. A tube-formation assay was performed to investigate the roles of PPAR $\gamma$ on the angiogenic potential of VECs. As demonstrated in Fig. 5A, following $6 \mathrm{~h}$ of culture on Matrigel-coated substrates, VECs exhibited capillary-like tubular structures when observed under a phase-contrast microscope. The quantitative parameters of angiogenesis, including the number of total tubes, total tube length, total branching points and total loops, were revealed to be potentiated following treatment 


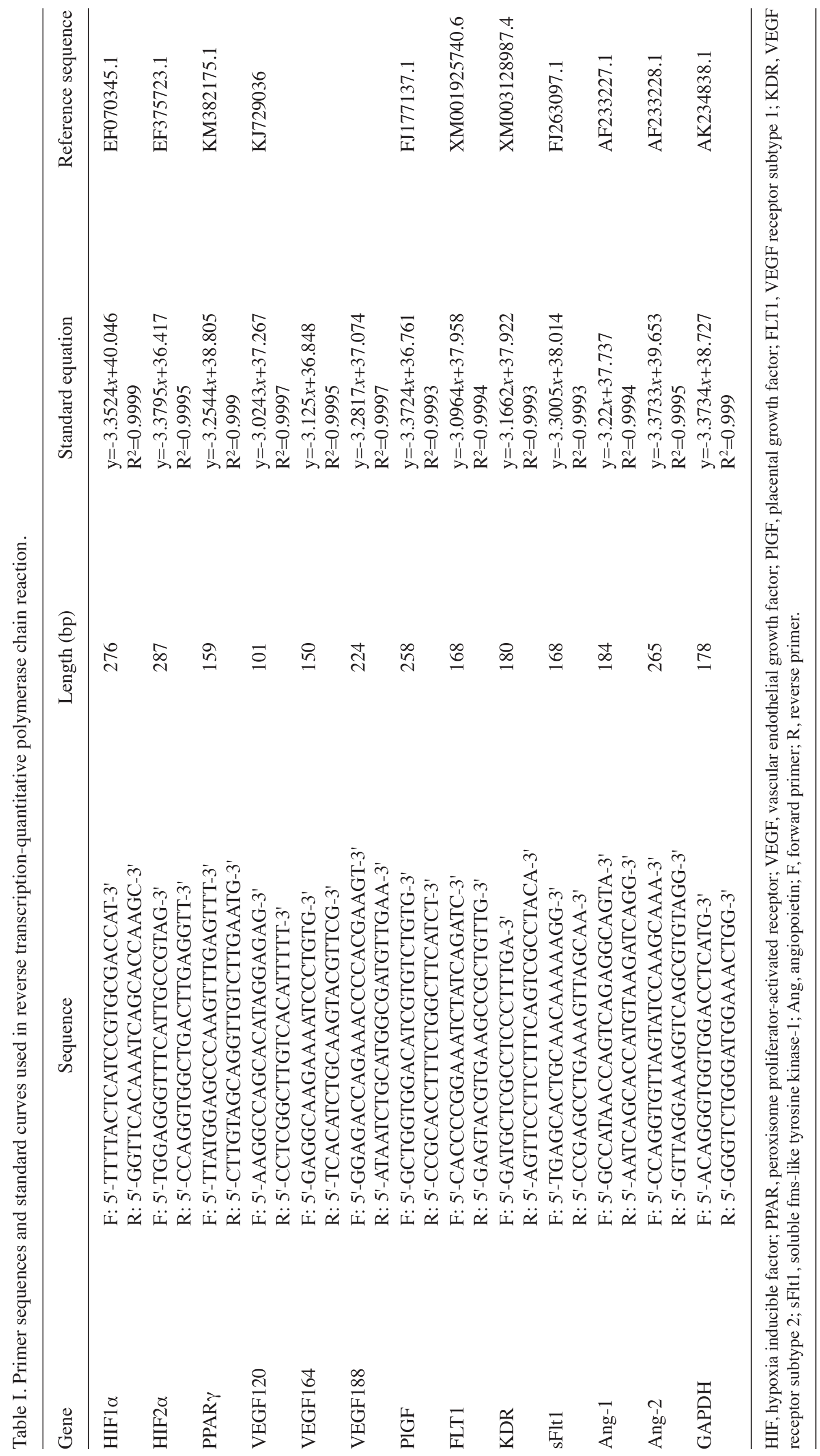




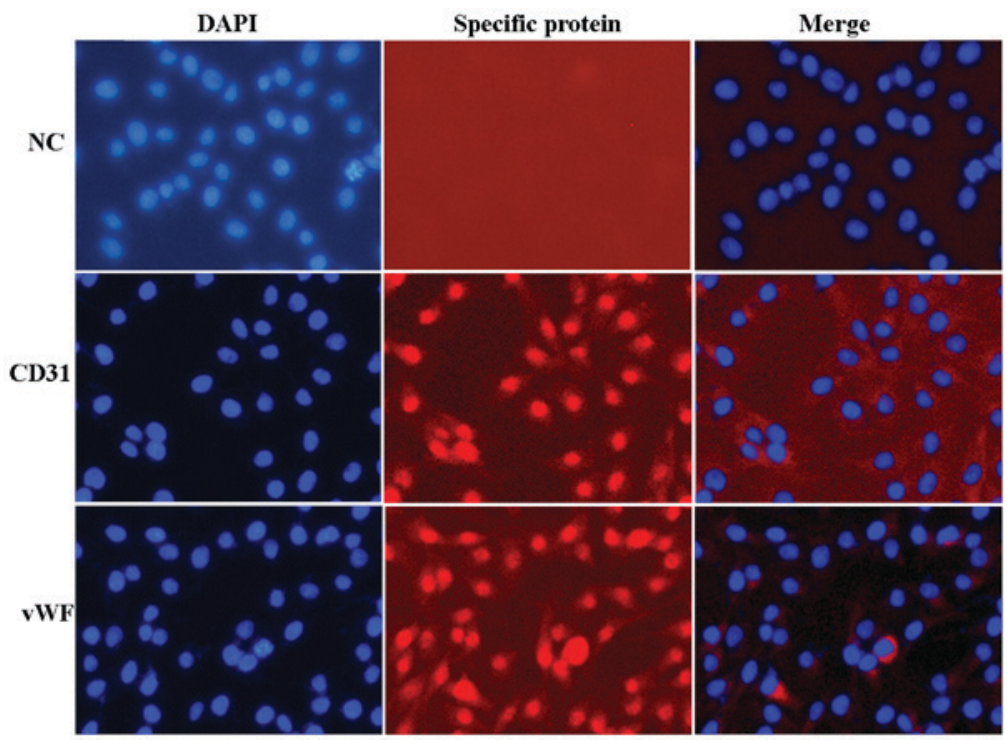

Figure 1. Immunofluorescent staining of VECs. The expression of vWF and CD31, indicated by red fluorescence, was observed in VECs with a fluorescent microscope under $\mathrm{x} 400$ magnification. DAPI was used to stain the cell nuclei. NC VECs were stained with negative serum instead of primary antibodies. VEC, vascular endothelial cell; vWF, von Willebrand factor; CD, cluster of differentiation; NC, negative control.
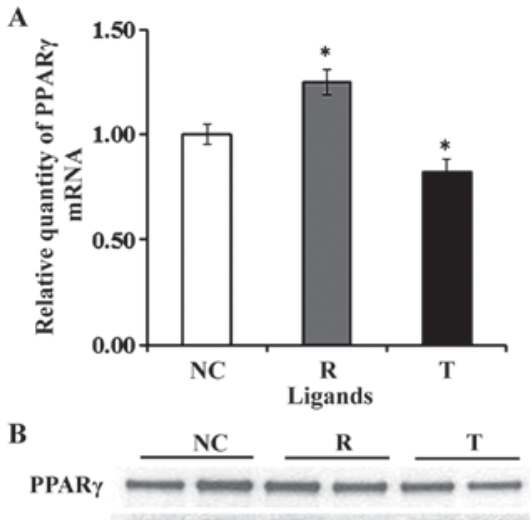

GAPDH

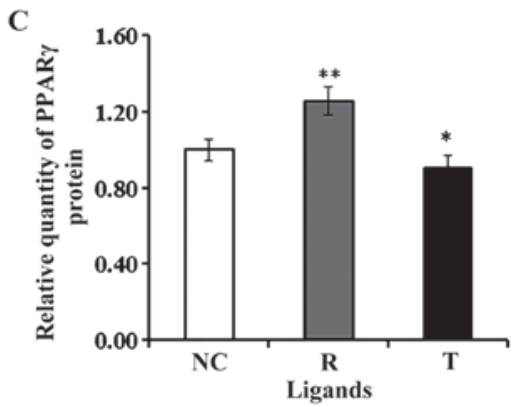

Figure 2. PPAR $\gamma$ expression in VECs following treatment with the PPAR $\gamma$ agonist rosiglitazone and the antagonist T0070907. (A) PPAR $\gamma$ mRNA expression levels were assessed using reverse transcription-quantitative polymerase chain reaction. (B) Western blot analysis of PPAR $\gamma$ protein expression levels. GAPDH served as an internal control. (C) Blots were semi-quantified using densitometry. NC cells were treated with dimethyl sulfoxide. Data are presented as the mean \pm standard error of at least 3 independent experiments. ${ }^{*} \mathrm{P}<0.05,{ }^{* *} \mathrm{P}<0.01$ vs. NC. PPAR, peroxisome proliferator-activated receptor; VEC, vascular endothelial cell; NC, negative control; R, rosiglitazone; T, T0070907.

of VECs with rosiglitazone for 6 and $10 \mathrm{~h}$ compared with control cells $(\mathrm{P}<0.05$; Fig. 5B-E). Notably, treatment with

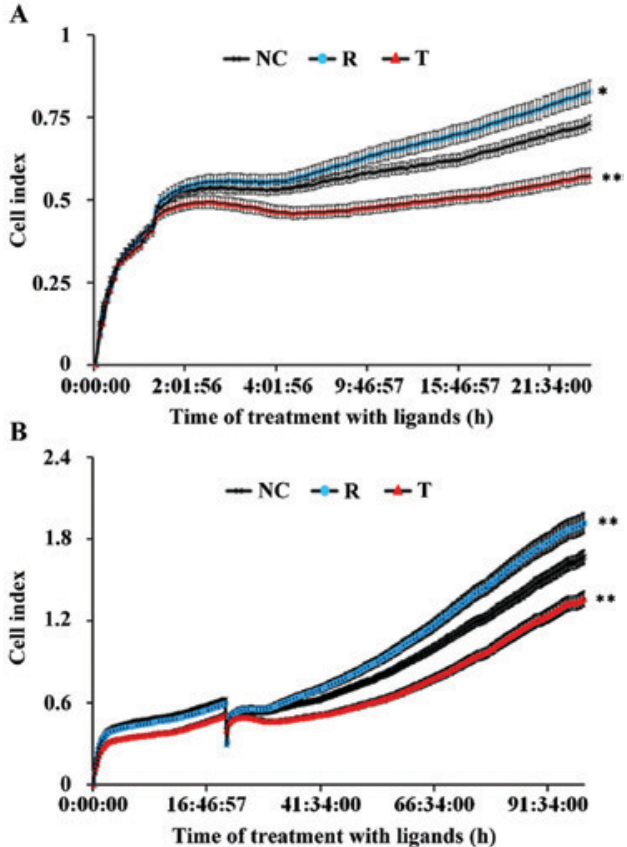

Figure 3. Effects of rosiglitazone and T0070907 on the adhesive and proliferative capabilities of VECs. VECs were treated with the PPAR $\gamma$ agonist rosiglitazone and the antagonist T0070907. NC cells were treated with dimethyl sulfoxide. Cellular impedance assays were used to evaluate VEC (A) adhesion and (B) proliferation. Data are presented as the mean \pm standard error of at least 3 independent experiments. ${ }^{*} \mathrm{P}<0.05,{ }^{* *} \mathrm{P}<0.01$ vs. NC. VEC, vascular endothelial cell; PPAR, peroxisome proliferator-activated receptor; NC, negative control; R, rosiglitazone; T, T0070907.

T0070907 for 6 and $10 \mathrm{~h}$ also resulted in a significant increase in tube, loop and branching point numbers, and in tube length compared with the control group $(\mathrm{P}<0.01$; Fig. 5B-E).

Angiogenic factor expression. The mRNA expression levels of several angiogenic factors were investigated using RT-qPCR in VECs following treatment with rosiglitazone and T0070907. 
A

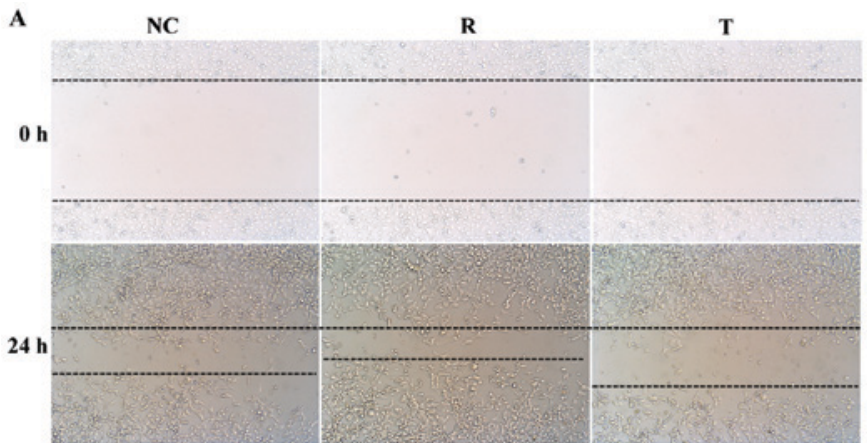

B

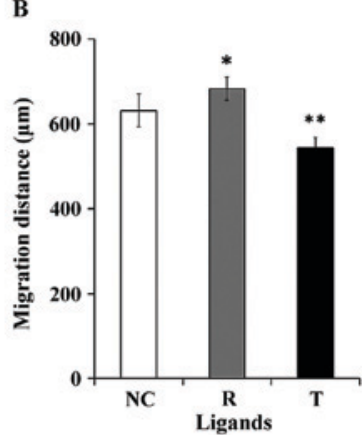

Figure 4. Effects of rosiglitazone and T0070907 on the migratory capabilities of VECs. VECs were treated with the PPAR $\gamma$ agonist rosiglitazone and the antagonist T0070907 and cellular migration was evaluated using a scratch-wound assay. NC cells were treated with dimethyl sulfoxide. (A) Representative photomicrographs of the wounded VEC monolayer immediately following the scratch $(0 \mathrm{~h})$ and following $24 \mathrm{~h}$ of treatment with rosiglitazone or T0070907. Magnification, $\mathrm{x} 100$. (B) The migration distance of VECs was analyzed following $24 \mathrm{~h}$ of treatment with rosiglitazone or T0070907. ${ }^{*} \mathrm{P}<0.05$, ${ }^{* *} \mathrm{P}<0.01 \mathrm{vs}$. NC. VEC, vascular endothelial cell; PPAR, peroxisome proliferator-activated receptor; NC, negative control; R, rosiglitazone; T, T0070907.

A
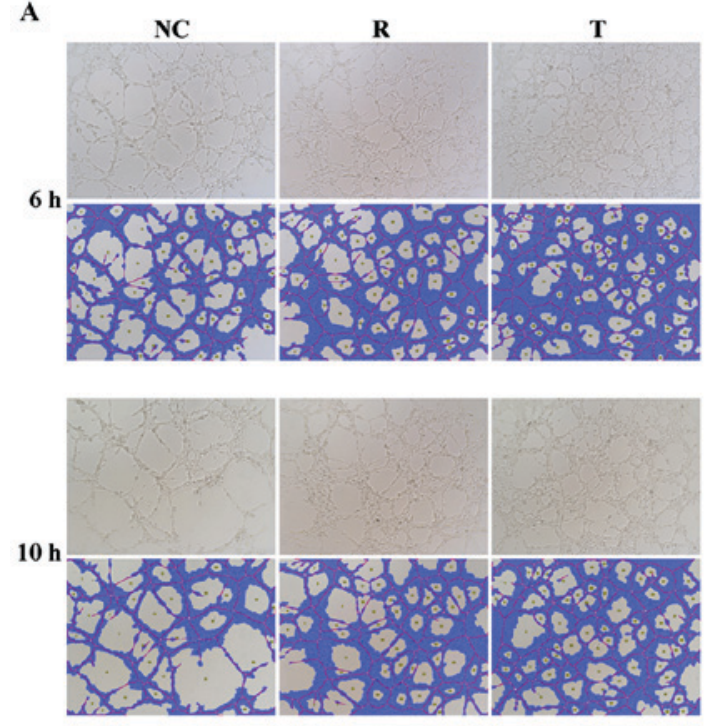

B
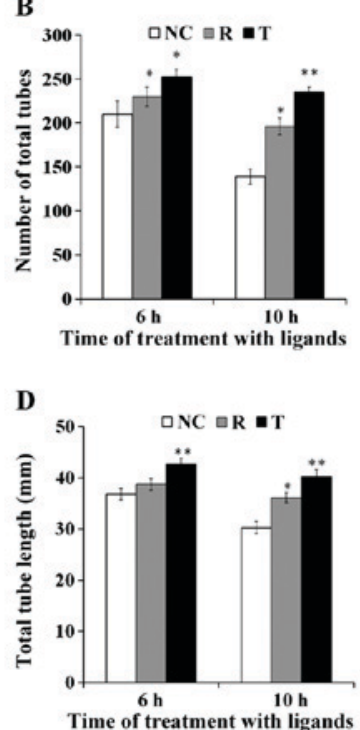

C

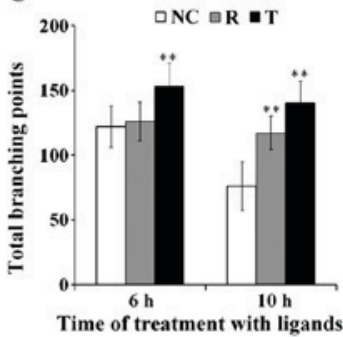

$\mathbf{E}$

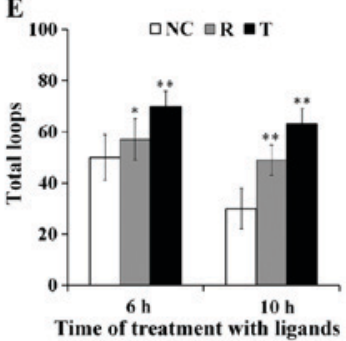

Figure 5. Effects of rosiglitazone and T0070907 on the tube-formation capabilities of VECs. VECs were treated with the PPAR $\gamma$ agonist rosiglitazone and the antagonist T0070907 and tube formation was following 6 and $10 \mathrm{~h}$ of treatment. NC cells were treated with dimethyl sulfoxide. (A) Representative photomicrographs were captured under x100 magnification. Quantitative parameters of tube formation were statistically analyzed: (B) Number of total tubes, (C) total tube length, (D) total number of branching points, (E) total number of loops. Data are presented as the mean \pm standard error of at least 3 independent experiments. ${ }^{*} \mathrm{P}<0.05,{ }^{* *} \mathrm{P}<0.01$ vs. $\mathrm{NC}$. VEC, vascular endothelial cell; PPAR, peroxisome proliferator-activated receptor; NC, negative control; $\mathrm{R}$, rosiglitazone; $\mathrm{T}, \mathrm{T} 0070907$.

As presented in Fig. 6A, the mRNA expression levels of HIF1 $\alpha$ and HIF2 $\alpha$ were significantly upregulated following treatment with rosiglitazone, whereas they were significantly downregulated following treatment with T0070907.

Treatment with rosiglitazone and T0070907 resulted in the significant downregulation of PIGF and VEGF120 mRNA expression; however, the VEGF188 mRNA levels were significantly upregulated following treatment with rosiglitazone, whereas they remained unaltered following PPAR $\gamma$ inhibition (Fig. 6B). Furthermore, the modulation of PPAR $\gamma$ activation did not appear to exert an effect on VEGF164 mRNA expression levels (Fig. 6B).

PPAR $\gamma$ inhibition resulted in the significant upregulation of FLT1 expression, whereas PPAR $\gamma$ activation had no effect on FLT1 mRNA levels (Fig. 6C). Following treatment with rosiglitazone, the mRNA expression levels of KDR were significantly increased, whereas T0070907 was demonstrated to suppress KDR expression (Fig. 6C). Conversely, the mRNA expression levels of sFlt1 were significantly downregulated in rosiglitazone-treated VECs, and significantly upregulated following T0070907 administration (Fig. 6C).

The mRNA expression levels of Ang-1 in VECs were significantly enhanced following PPAR $\gamma$ activation, and significantly suppressed in T0070907-treated cells (Fig. 6D). However, Ang-2 mRNA expression was consistently decreased following PPAR $\gamma$ activation and blockade (Fig. 6D).

\section{Discussion}

In a previous study, the PPAR $\gamma$ agonist troglitazone exhibited species-specific effects in human and mouse endothelial cells, as it was reported to increase the proliferation and survival 

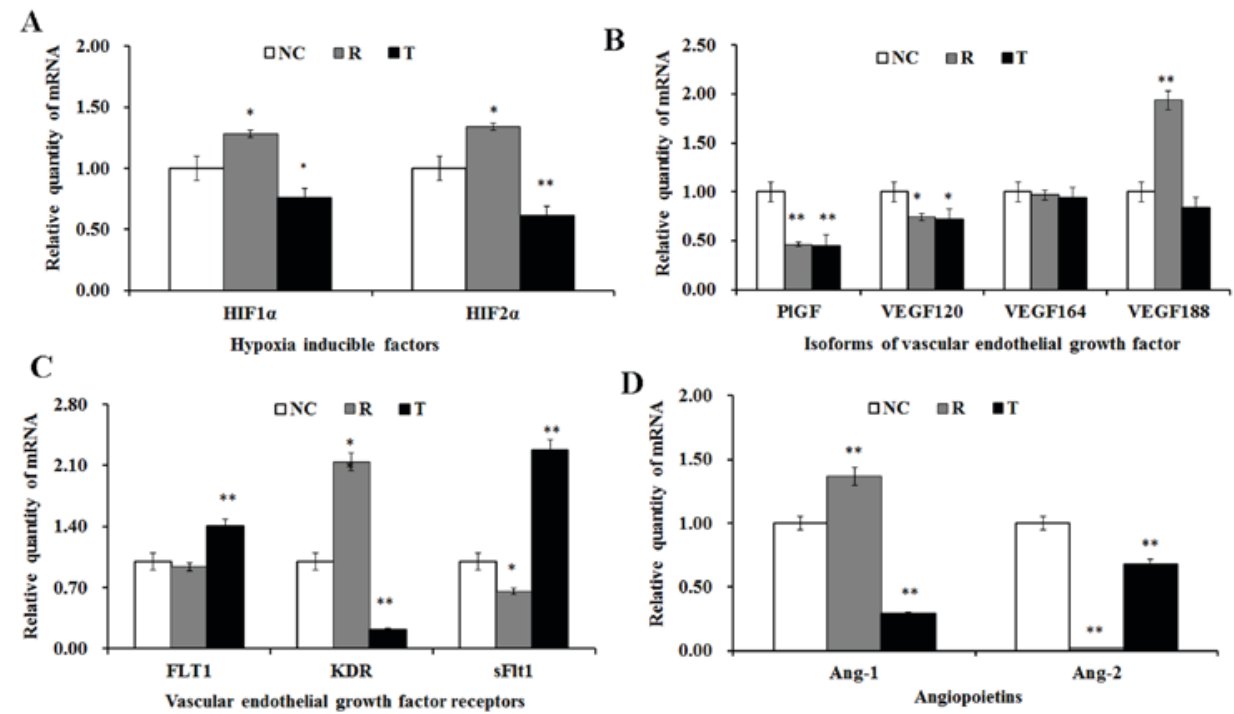

Figure 6. Effects of rosiglitazone and T0070907 on mRNA expression of angiogenic factors in VECs. VECs were treated with the PPAR $\gamma$ agonist rosiglitazone and the antagonist T0070907. mRNA expression levels of (A) HIFs, (B) VEGF isoforms, (C) VEGFR subtypes and (D) Ang subtypes were assessed using reverse transcription-quantitative polymerase chain reaction following $24 \mathrm{~h}$ of treatment. NC cells were treated with dimethyl sulfoxide. Data are presented as the mean \pm standard error of at least 3 independent experiments. ${ }^{*} \mathrm{P}<0.05,{ }^{* *} \mathrm{P}<0.01 \mathrm{vs}$. NC. VEC, vascular endothelial cell; PPAR, peroxisome proliferator-activated receptor; HIF, hypoxia-inducible factor; VEGF, vascular endothelial growth factor; VEGFR, VEGF receptor; Ang, angiopoietin; NC, negative control; R, rosiglitazone; T, T0070907; PIGF, placental growth factor; FLT1, VEGFR subtype 1; KDR, VEGFR subtype 2; sFlt1, soluble fms-like tyrosine kinase-1.

of mouse mammary fat pad microvascular endothelial cells, whereas it did not affect human dermal microvascular endothelial cells (34). In the present study, the PPAR $\gamma$ agonist rosiglitazone was revealed to enhance the adhesive, proliferative and migratory capabilities of porcine VECs; conversely, the PPAR $\gamma$ antagonist T0070907 inhibited VEC adhesion, proliferation and migration. These results suggested that PPAR $\gamma$ may exert proangiogenic effects during porcine placental development. In accordance with a previous study reporting dysregulation of placental layers and vasculature defects in PPAR $\gamma^{-/}$mice (20), the present findings suggested that PPAR $\gamma$ may promote placental vascularization in porcine VECs, possibly via enhancing VEC differentiation, proliferation and energy metabolism.

Currently, the role of PPAR $\gamma$ during angiogenesis remains controversial. Previous studies have suggested that PPAR $\gamma$ activation may inhibit angiogenesis, as demonstrated by the inhibition of capillary-like tube formation in human retinal pigment epithelial and bovine choroidal endothelial cells (35), and by the suppression of the proliferative and migratory capabilities of human umbilical vein endothelial cells $(36,37)$. However, contradictory studies have suggested proangiogenic effects for PPAR $\gamma$, exerted through the regulation of VEGF expression in myocardial (38) and pulmonary capillary cells (39). These discrepancies may be attributed to inter-species and cell type-specific differences, and the different types and doses of PPAR $\gamma$ ligands that were used in the various studies. Notably, in the present study, the quantitative parameters of angiogenesis appeared to be invariably enhanced following the activation and inhibition of PPAR $\gamma$ in VECs. These effects may be associated with the various VEGF isoforms and their receptors: PIGF and VEGF120 mRNA expression levels were downregulated following PPAR $\gamma$ activation and blockade; however, PPAR $\gamma$ activation may promote tube formation through the potentiation of VEGF188/KDR signaling. Conversely, PPAR $\gamma$ blockade may enhance capillary-like tube formation via promoting VEGF164/FLT1 and VEGF188/FLT1 signaling.

Angiogenesis is an adaptive response to hypoxia in vivo and in vitro, and HIFs are the key mediators responsible for the activation of several angiogenic factors, including VEGFA (40). However, the various HIF isoforms may be characterized by differential expression and distinct functions (41). In the present study, the mRNA expression levels of HIF1 $\alpha$ and HIF $2 \alpha$ were modulated by PPAR $\gamma$ activation or inhibition, indicating that HIF and PPAR $\gamma$ were both involved in the recruitment of growth factors and induction of vascularization. Therefore, VEC adhesion, proliferation and migration may be modified by the synergistic effect of HIF and PPAR $\gamma$.

Three stable VEGFA isoforms, namely VEGF120, VEGF164 and VEGF188, have been identified in the porcine peri-implantation conceptus $(14,42)$. VEGFA has been implicated in angiogenesis; however, the various VEGFA isoforms are characterized by distinct properties and expression patterns (43). In addition, the VEGFA isoforms differ with regard to their binding affinity for the various VEGFR subtypes $(14,43)$. In the present study, three VEGF isoforms, namely PIGF, VEGF120 and VEGF188, were revealed to be modulated by PPAR $\gamma$ activation or inhibition; whereas VEGF164 did not appear to be affected by PPAR $\gamma$ modulation. These results may indicate that PPAR $\gamma$ mediates vascularization through the modulation of VEGF120/VEGFRs, VEGF188/VEGFRs and PlGF/VEGFRs, similarly with the situation observed during early pregnancy in the pig $(42,44)$. These results suggested that various VEGF isoforms and VEGFR subtypes may be differentially implicated in the various stages of the angiogenic process, and may differentially regulate vascularization.

In present study, the mRNA expression levels of Ang-1 and Ang-2 were assessed in VECs, as has previously been 
reported in perivascular and endothelial tip cells (45). The balance between Ang-1 and Ang-2 is critical for vascular stability, and Ang-1/Ang-2 imbalance has been associated with vascular disruption and the initiation of angiogenesis in tumor tissues (46). In addition, aberrant angiogenesis has been reported in Ang-1/- mice (47). In the present study, PPAR $\gamma$ modulation was demonstrated to exert distinct effects on Ang-1 and Ang- 2 mRNA expression, whereby PPAR $\gamma$ activation significantly upregulated Ang-1 and downregulated Ang-2.

In conclusion, the present results suggested that PPAR $\gamma$ may bind to a PPAR-responsive element in the VEGFA promoter region (23), and promote the translation of the VEGF188 isoform instead of VEGF120 or VEGF164, thus promoting VEGFA/KDR and VEGFA/Flt1 interactions, and increasing capillary density and the total number of capillary-like tubes. Furthermore, PPAR $\gamma$ may interact with HIFs and thus activate VEGF transcription. Therefore, the present findings suggested that PPAR $\gamma$ may be implicated in angiogenesis, through the promotion of endothelial cell adhesion, proliferation and migration, and through enhancing the formation and the stability of capillary-like tubules. However, further studies are required to elucidate the detailed molecular mechanisms that underlie the involvement of PPAR $\gamma$ in angiogenic processes.

\section{Acknowledgements}

The present study was supported by the Natural Science Foundation of China (grant nos. 31172377, 31272630 and 31572591) and the Key Projects of Hunan Province Education Office (grant no. 14A069).

\section{References}

1. Risau W and Flamme I: Vasculogenesis. Annu Rev Cell Dev Biol 11: 73-91, 1995.

2. Risau W: Mechanisms of angiogenesis. Nature 386: 671-674, 1997.

3. Sato Y, Poynter G, Huss D, Filla MB, Czirok A, Rongish BJ, Little CD, Fraser SE and Lansford R: Dynamic analysis of vascular morphogenesis using transgenic quail embryos. PLoS One 5: e12674, 2010.

4. Charnock-Jones DS, Clark DE, Licence D, Day K, Wooding FB and Smith SK: Distribution of vascular endothelial growth factor (VEGF) and its binding sites at the maternal-fetal interface during gestation in pigs. Reproduction 122: 753-760, 2001.

5. Ventureira MR, Sobarzo CMA, Naito M, Zanuzzi C, Barbeito $\mathrm{C}$ and Cebral E: Early placental angiogenesis-vascularization and VEGF/KDR receptor expression during mouse organogenesis after perigestational alcohol consumption. Placenta 36: 491, 2015.

6. Saharinen P and Alitalo K: The yin, the yang, and the angiopoietin-1. J Clin Invest 121: 2157-2159, 2011.

7. Hwang B, Lee SH, Kim JS, Moon JS, Jeung IC, Lee NG, Park J, Hong HJ, Cho YL, Park YJ, et al: Stimulation of angiogenesis and survival of endothelial cells by human monoclonal Tie2 receptor antibody. Biomaterials 51: 119-128, 2015.

8. Yancopoulos GD, Davis S, Gale NW, Rudge JS, Wiegand SJ and Holash J: Vascular-specific growth factors and blood vessel formation. Nature 407: 242-248, 2000.

9. Jiang YZ, Li Y, Wang K, Dai CF, Huang SA, Chen DB and Zheng J: Distinct roles of HIF1A in endothelial adaptations to physiological and ambient oxygen. Mol Cell Endocrinol 391: 60-67, 2014.

10. Burton GJ, Charnock-Jones D and Jauniaux E: Regulation of vascular growth and function in the human placenta. Reproduction 138: 895-902, 2009.

11. Soleymanlou N, Jurisica I, Nevo O, letta F, Zhang X, Zamudio S Post $M$ and Caniggia I: Molecular evidence of placental hypoxia in preeclampsia. J Clin Endocrinol Metab 90:4299-4308, 2005.
12. Semenza GL: Hypoxia-inducible factors in physiology and medicine. Cell 148: 399-408, 2012.

13. Koch S and Claesson-Welsh L: Signal transduction by vascular endothelial growth factor receptors. Cold Spring Harb Perspect Med 2: a006502, 2012.

14. Vempati P, Popel AS and Mac Gabhann F: Extracellular regulation of VEGF: Isoforms, proteolysis, and vascular patterning. Cytokine Growth Factor Rev 25: 1-19, 2014.

15. Grünewald FS, Prota AE, Giese A and Ballmer-Hofer K: Structure-function analysis of VEGF receptor activation and the role of coreceptors in angiogenic signaling. Biochim Biophys Acta 1804: 567-580, 2010.

16. Ng YS, Rohan R, Sunday ME, Demello DE and D'amore PA: Differential expression of VEGF isoforms in mouse during development and in the adult. Dev Dyn 220: 112-121, 2001.

17. Nieminen T, Toivanen PI, Rintanen N, Heikuraa T, Jauhiainena S, Airennea KJ, Alitaloc K, Marjomäkib V and Ylä-Herttuala S: The impact of the receptor binding profiles of the vascular endothelial growth factors on their angiogenic features. Biochim Biophys Acta 1840: 454-463, 2014.

18. Huang Y, Zhao B, Liu Y and Wang N: Peroxisome proliferator-activated receptor gamma regulates the expression of lipid phosphate phosphohydrolase 1 in human vascular endothelial cells. PPAR Res 2014: 740121, 2014.

19. Kepez A, Oto A and Dagdelen S: Peroxisome proliferator-activated receptor-gamma: Novel therapeutic target linking adiposity, insulin resistance, and atherosclerosis. BioDrugs 20: 121-135, 2006.

20. Nadra K, Quignodon L, Sardella C, Joye E, Mucciolo A, Chrast R and Desvergne B: PPARgamma in placental angiogenesis. Endocrinology 151: 4969-4981, 2010.

21. Meher A, Sundrani D and Joshi S: Maternal nutrition influences angiogenesis in the placenta through peroxisome proliferator activated receptors: A novel hypothesis. Mol Reprod Dev 82: 726-734, 2015.

22. Tache V, Ciric A, Moretto-Zita M, Li Y, Peng J, Maltepe E, Milstone DS and Parast MM: Hypoxia and trophoblast differentiation: A key role for PPAR $\gamma$. Stem Cells Dev 22: 2815-2824, 2013.

23. Hasan AU, Ohmori K, Konishi K, Igarashi J, Hashimoto T, Kamitori K, Yamaguchi F, Tsukamoto I, Uyama T, Ishihara Y, et al: Eicosapentaenoic acid upregulates VEGF-A through both GPR120 and PPAR $\gamma$ mediated pathways in 3T3-L1 adipocytes. Mol Cell Endocrinol 406: 10-18, 2015.

24. Cines DB, Pollak ES, Buck CA, Loscalzo J, Zimmerman GA, McEver RP, Pober JS, Wick TM, Konkle BA, Schwartz BS, et al: Endothelial cells in physiology and in the pathophysiology of vascular disorders. Blood 91: 3527-3561, 1998.

25. Zhang J, Xu J, Yang Q, Yuan A, Yang L and Xue L: Peroxisome proliferator-activated receptor gamma (PPAR $\gamma$ ) expression in pig placenta. Mol Med Rep MMR-8037-156015 in press.

26. Hong HX, Zhang YM, Xu H, Su ZY and Sun P: Immortalization of swine umbilical vein endothelial cells with human telomerase reverse transcriptase. Mol Cells 24: 358-363, 2007.

27. Chrusciel M, Bodek G, Kirtiklis L, Lewczuk B, Hyder CL, Blitek A, Kaczmarek MM, Ziecik AJ and Andronowska A: Immortalization of swine umbilical vein endothelial cells (SUVECs) with the simian virus 40 large-T antigen. Mol Reprod Dev 78: 597-610, 2011.

28. Young PW, Buckle DR, Cantello BC, Chapman H, Clapham JC, Coyle PJ, Haigh D, Hindley RM, Holder JC, Kallender H, et al: Identification of high-affinity binding sites for the insulin sensitizer rosiglitazone (BRL-49653) in rodent and human adipocytes using a radioiodinated ligand for peroxisomal proliferator-activated receptor gamma. J Pharmacol Exp Ther 284: 751-759, 1998.

29. Zaytseva YY, Wallis NK, Southard RC and Kilgore MW: The PPARgamma antagonist T0070907 suppresses breast cancer cell proliferation and motility via both PPARgamma-dependent and -independent mechanisms. Anticancer Res 31: 813-823, 2011.

30. Dolkart O, Liron T, Chechik O, Somjen D, Brosh T, Maman and Gabet Y: Statins enhance rotator cuff healing by stimulating the COX2/PGE2/EP4 pathway: An in vivo and in vitro study. Am J Sports Med 42: 2869-2876, 2014

31. Koval OA, Sakaeva GR, Fomin AS, Nushtaeva AA, Semenov DV, Kuligina EV, Gulyaeva LF, Gerasimov AV and Richter VA: Sensitivity of endometrial cancer cells from primary human tumor samples to new potential anticancer peptide lactaptin. J Cancer Res Ther 11: 345-351, 2015.

32. Livak KJ and Schmittgen TD: Analysis of relative gene expression data using real-time quantitative PCR and the 2(-Delta Delta C(T)) method. Methods 25: 402-408, 2001. 
33. Jonkman JE, Cathcart JA, Xu F, Bartolini ME, Amon JE, Stevens KM and Colarusso P: An introduction to the wound healing assay using live-cell microscopy. Cell Adh Migr 8: 440-451, 2014.

34. Kakiuchi-Kiyota S, Vetro JA, Suzuki S, Varney ML, Han HY Nascimento M, Pennington KL, Arnold LL, Singh RK and Cohen SM: Effects of the PPARgamma agonist troglitazone on endothelial cells in vivo and in vitro: Differences between human and mouse. Toxicol Appl Pharmacol 237: 83-90, 2009.

35. Murata T, He S, Hangai M, Ishibashi T, Xi XP, Kim S, Hsueh WA, Ryan SJ, Law RE and Hinton DR: Peroxisome proliferator-activated receptor-gamma ligands inhibit choroidal neovascularization. Invest Ophthalmol Vis Sci 41: 2309-2317, 2000.

36. Park BC, Thapa D, Lee JS, Park SY and Kim JA: Troglitazone inhibits vascular endothelial growth factor-induced angiogenic signaling via suppression of reactive oxygen species production and extracellular signal-regulated kinase phosphorylation in endothelial cells. J Pharmacol Sci 111: 1-12, 2009.

37. Kim KY, Ahn JH and Cheon HG: Anti-angiogenic action of PPAR $\gamma$ ligand in human umbilical vein endothelial cells is mediated by PTEN upregulation and VEGFR-2 downregulation. Mol Cell Biochem 358: 375-385, 2011.

38. Zhang H, Wei T, Jiang X, Li Z, Cui H, Pan J, Zhuang W, Sun T, Liu Z, Zhang Z and Dong H: PEDF and 34-mer inhibit angiogenesis in the heart by inducing tip cells apoptosis via up-regulating PPAR- $\gamma$ to increase surface FasL. Apoptosis 21: 60-68, 2016.

39. Biscetti F, Gaetani E, Flex A, Aprahamian T, Hopkins T, Straface G, Pecorini G, Stigliano E, Smith RC, Angelini F, et al: Selective activation of peroxisome proliferator-activated receptor (PPAR)alpha and PPARgamma induces neoangiogenesis through a vascular endothelial growth factor-dependent mechanism. Diabetes 57: 1394-1404, 2008
40. Ndubuizu OI, Tsipis CP,Li A and LaManna JC: Hypoxia-inducible factor-1 (HIF-1)-independent microvascular angiogenesis in the aged rat brain. Brain Res 1366: 101-109, 2010.

41. Arreola A, Cowey CL, Coloff JL, Rathmell JC and Rathmell WK: HIF1 $\alpha$ and HIF $2 \alpha$ exert distinct nutrient preferences in renal cells. PLoS One 9: e98705, 2014.

42. Kaczmarek MM, Kiewisz J, Schams D and Ziecik AJ: Expression of VEGF-receptor system in conceptus during peri-implantation period and endometrial and luteal expression of soluble VEGFR-1 in the pig. Theriogenology 71: 1298-1306, 2009.

43. Kanthou C, Dachs GU, Lefley DV, Steele AJ, Coralli-Foxon C, Harris S, Greco O, Dos Santos SA, Reyes-Aldasoro CC, English WR and Tozer GM: Tumour cells expressing single VEGF isoforms display distinct growth, survival and migration characteristics. PLoS One 9: e104015, 2014.

44. Coultas L, Chawengsaksophak K and Rossant J: Endothelial cells and VEGF in vascular development. Nature 438: 937-945, 2005.

45. Augustin HG, Koh GY, Thurston G and Alitalo K: Control of vascular morphogenesis and homeostasis through the angiopoietin-Tie system. Nat Rev Mol Cell Biol 10: 165-177, 2009.

46. Holash J, Maisonpierre P, Compton D, Boland P, Alexander CR, Zagzag D, Yancopoulos GD and Wiegand SJ: Vessel cooption, regression, and growth in tumors mediated by angiopoietins and VEGF. Science 284: 1994-1998, 1999.

47. Jeansson M, Gawlik A, Anderson G, Li C, Kerjaschki D, Henkelman M and Quaggin SE: Angiopoietin-1 is essential in mouse vasculature during development and in response to injury. J Clin Invest 121: 2278-2289, 2011. 